\title{
Motricidades del Sur: Congada de San Benedicto en Ilhabela - Brasil Motricities of the South: Congada of St. Benedict in Ilhabela - Brazil
}

*Silmara Elena Alves de Campos, **Denise Aparecida Corrêa, ***Luiz Gonçalves Junior

*Prefectura Municipal de Ilhabela (Brasil), **Universidad Estadual Paulista (Brasil), ***Universidad Federal de São Carlos

Resumen. Motricidades del Sur son prácticas sociales de juegos, luchas, danzas, fiestas, cantos, historias y rituales con características propias de un pueblo/ comunidad ubicada al sur, geográfica o metafóricamente, que involucran tradición y resistencia de tales manifestaciones al colonialismo y dominación epistemológica. El objetivo de esta investigación es comprender los procesos educativos involucrados en la construcción de las Motricidades del Sur de participantes de la Congada de San Benedicto en Ilhabela, ubicada en litoral norte del estado de São Paulo, Brasil. Con metodología de inspiración fenomenológica, fueron entrevistadas cinco personas involucradas con la práctica de la Congada. Las entrevistas fueron sometidas a análisis fenomenológica posibilitando la construcción de la categoría: «Ancestralidad, devoción y pertenencia en fiesta». Es posible considerar que las Motricidades del Sur, en la Congada de San Benedicto, involucrasen la tradición y la resistencia de un pueblo. Estos aspectos están bien mantenidos, son criados, recreados, rememorados, se hacen presentes y se proyectan entre sus participantes en el proceso cotidiano de vivir-la-vida.

Palabras clave: Procesos Educativos, Congada, Motricidades del Sur, Epistemologías del Sur.

\begin{abstract}
Motricities of the South are social practices of games, fights, dances, parties, songs, stories and rituals with characteristics of a people / community located to the south, geographically or metaphorically, that involve tradition and resistance of such manifestations to colonialism and epistemological domination. The objective of this research is to understand the educational processes involved in the construction of the Motricities of the South of participants of the Congada de San Benedicto in Ilhabela, located on the north coast of the state of São Paulo, Brazil. With a phenomenological-inspired methodology, five people involved with the practice of the Congada were interviewed. The interviews were subjected to phenomenological analysis allowing the construction of the category: «Ancestrality, devotion and belonging to a party». It is possible to consider that the Motricities of the South, in the Congada de San Benedicto, involved the tradition and resistance of a people. These aspects are well maintained, they are raised, recreated, remembered, made present and projected among its participants in the daily process of living-life.
\end{abstract}

Keywords: Educational Processes, Congada, Motricities of the South, Epistemologies of the South.

\section{Introducción}

La cuestión que se aborda en este trabajo parte de tenerse en cuenta el contexto de América Latina que nos encontramos y donde emergen nuestras reflexiones que tienen como premisa el compromiso con personas (socialmente marginadas), comunidades (populares, indígenas y afrodescendientes) y conocimientos por ellas construidas, que corren en el mundo de la experiencia e implican epistemologías propias.

Sin embargo, como indica Santos (2004: 17), la ciencia moderna, eurocéntrica ${ }^{1}$ y postulada como el único estatus epistemológico válido, aunque propague conocer más y mejor el mundo para en este intervenir por el bien común, cada vez se aleja de este propósito, lo

Fecha recepción: 10-07-21. Fecha de aceptación: 21-01-22

Denise Aparecida Corrêa

denise.correa@unesp.br que dificulta la distribución equitativa del conocimiento producido en y para la sociedad, ya que «[...] el privilegio epistemológico que se arroga la ciencia moderna asume que la ciencia se hace en el mundo, pero no se hace del mundo».

La ciencia eurocéntrica, al suprimir los saberes contrarios a los intereses del colonialismo, del capitalismo y del patriarcado, de modo ideológico, ha marginado otras formas de producción de conocimiento que, como contrapunto, pueden favorecer una producción científica comprometida con un proyecto de sociedad más justo, puesto que tal producción, de acuerdo con Oliveira et al. (2014: 43) está hecho por personas que viven «[...] las experiencias encarnadas de 'marginación', 'descalificación' y 'exclusión', así como de sus resistencias, luchas y reclamaciones».

Como señala Walsh (2017: 25), con la transformación de las tierras de Abya Yala en América, por parte de los invasores, se iniciaron procesos emancipatorios y de 
resistencia de los pueblos originales, en cuyas estrategias, prácticas y metodologías se encuentran:

[...] pedagogías de lucha, rebeldía, cimarronaje, insurgencia, organización y acción que los pueblos originarios primero, y luego los africanos y las africanas secuestradxs, emplearon para resistir, transgredir y subvertir la dominación, para seguir siendo, sintiendo, haciendo, pensando y viviendo -decolonialmente- a pesar del poder colonial.

En este sentido son relevantes los procesos educativos que emergen de manifestaciones cuyos saberes incrustados en las experiencias de los sujetos sean, ellos mismos, impugnadores del orden social dominante. En particular, en este texto, ponemos los saberes de la Congada de San Benedicto en Ilhabela, como una manifestación de la cultura popular de origen africana, que, de acuerdo con Correa (1981) se lleva a cabo desde hace más de 170 años y dramatiza en sus bailes la historia de dos grupos (moros y paganos) que pelean porque ambos quieren celebrar San Benedicto.

Fundamental también considerar el principio de la ancestralidad, representado metafóricamente, según Tedla (1995), por el ave del territorio africano llamada sankofa. Sankofa se alimenta de las semillas que le caen en las espaldas y, en la filosofía africana, tal acción tiene el sentido de volverse para alimentarse, alimentándose también de su ancestralidad, valorando sus raíces. La analogía se refiere a la idea de que la sociedad solo existe frente a la continuidad vital y solidaria con los antepasados. Para el pensamiento africano, toda la vida es interconectada e interdependiente.

Lo indígena Ailton Krenak expresa el sentido de ancestralidad como la valoración de las raíces y de los conocimientos de los antepasados como continuidad de la vida en lo presente:

Nuestros antepasados no son solo la generación que nos precedió ahora, nuestro abuelo, nuestro bisabuelo. Es una gran corriente de seres que ya pasaron por aquí [...]. Se transmitieron a través de prácticas, rituales, cultura, y entendemos que es un continuo de nuestros antepasados [...]. Hasta el día de hoy, entendemos que estamos en este mismo continuo de interacción con la memoria de nuestro pueblo, con la memoria de nuestra cultura (Krenak, 2020: 28-29).

Involucrar el principio de la ancestralidad en la perspectiva de los pueblos africanos, afrobrasileños e indígenas, presente en el contexto latinoamericano y caizara, contribuye para avanzar lo inmediato postulado por la sociedad moderna occidental, la cual nos tiene apartado de nuestras raíces y del sentido de pertenencia a una comunidad de saberes-motricidades.

Tedla (1995) agrega que, en la visión africana, las personas se refieren a un principio de comunidad, COlectividad, a «nosotros», es decir, «soy porque somos», asumiendo una relación orgánica entre los miembros. En esta perspectiva, ser persona es estar dispuesto a compartir, a ayudar a los demás y a uno mismo, en una comprensión de comunidad.

En este sentido, vemos otro principio de la filosofía africana, el principio ubuntu. Para Tutu (2012: 41): «Una persona es una persona a través de otras personas», es decir, la humanidad de una persona se alcanza y se asocia con otra persona de manera insoluble y diferencia lo «Yo pienso, pronto existo», de Descartes, pues ubuntu expresa la idea «existo porque pertenezco», o sea: «Puedo ser yo solo porque lo somos, porque estamos hechos para la complementariedad. Somos creados para una delicada red de relaciones, de interdependencia con nuestros semejantes, con el resto de la creación» (Tutu, 2012: 42).

Aun, como afirma Senghor (1965), para el que «pienso, pronto existo» de marcado acento eurocéntrico cartesiano, no tiene sentido en una visión del mundo africana. Para él autor, «El negro africano podría decir: 'Me siento, yo bailo el Otro, yo soy'. Bailar es descubrir y recrear» (p. 84).

La Congada de San Benedicto en Ilhabela es una manifestación que se perpetúa de generación en generación (Campos, 2017) y como nos indica Merlo (2000: 72) los congueros en «[...] memoria de sus antepasados y por la devoción al santo, prosiguen en este esfuerzo colectivo para mantener la tradición, pero recelan su final. Este evento cargado de símbolos impregna la historia de este pueblo y los lazos entre negros y blancos, entre religiones y hoy en día, entre los turistas y caizaras».

Las comunidades caizaras nacieron a partir del siglo XVI, producto del mestizaje de blancos (principalmente portugueses), indígenas (principalmente tupinambás) y negros transportados como esclavizados desde África al Brasil. El término caizara proviene de la lengua indígena tupi, que denominaba originariamente las ramas de árboles colocados en el mar para cercar los peces. Posteriormente pasó a ser utilizado, también, por los habitantes y comunidades de zonas litorales de los estados de São Paulo, Rio de Janeiro y Paraná, los cuales, en el pasado, tenían un modo de vida exclusivamente ligado a la pesca y la agricultura (Adams, 2000; Diegues, 2005; Campos, 2008; Campos, 2017; Gonçalves-Junior et al., 2012). 
Estamos en acuerdo con Freire \& Faundez (1985) cuando ellos argumentan que en las manifestaciones culturales, incluida la religiosidad, además de las marcas de la ideología dominante, también encontrase la resistencia popular. Dussel (s/d: 277) en una perspectiva que valora la cultura popular nos muestra que esta «[...] lejos de ser una cultura de menor importancia, es el centro más no contaminado y que irradia la resistencia de los marginados contra la opresión».

\section{Motricidades del Sur: trayectorias teóricas}

El proyecto de contraposición epistemológica requiere mirar hacia el sujeto de la experiencia, investigando con otros, en diálogo horizontal, los saberes-motricidades que se resistieron con éxito al norte epistemológico.

En este sentido, la Motricidad, para Sérgio (1996: 17-18), no es un sirviente que lleva el cuerpo de un punto del espacio a otro, sino que es «[...] la experiencia original, de la que emerge también la historia de las conductas motoras del sujeto, ya que no hay experiencia vivida sin intersubjetividad que la praxis asume».

Motricidades del Sur es un concepto en construcción por nosotros, desde Gonçalves-Junior (2010) y Gonçalves-Junior et al. (2012), inicialmente bajo la denominación etnomotricidad, pasando a etnomotricidades del sur en el «VI Coloquio de Investigación Cualitativa en Motricidad Humana» (CPQMH), edición de 2015 (Valdivia, Chile), y que ahora nombramos Motricidades del Sur, por adecuación conceptual sugerida por el propio proponente de las Epistemologías del Sur, Prof. Dr. Boaventura de Sousa Santos, en un encuentro científico, en el Centro de Estudios Sociales de la Universidad de Coimbra (CES/UC), en el 2 de agosto de 2016, con Prof. Dr. Luiz Gonçalves-Junior y Profa. Dra. Denise Aparecida Corrêa. Además, la expresión y el concepto sigue en discusión y profundización en las reuniones del «Núcleo de Estudios de Fenomenología en Educación Física» (NEFEF), de la «Sociedad de Investigación Cualitativa en Motricidad Humana» (SPQMH) y en los CPQMH, ediciones 2017 (Sergipe, Brasil) y 2019 (Maputo, Mozambique), así como en las tesis doctorales de Campos (2017), Carmo (2017) y Belmonte (2019).

Así, asumimos tales referencias, sobre todo con aportes de las Epistemologías del Sur, en las cuales Santos \& Meneses (2010: 19) designan el Sur:

[...] metafóricamente como un campo de desafíos epistémicos, que buscan reparar los daños y los impactos históricamente causados por el capitalismo en su relación colonial con el mundo. Esta concepción del Sur se superpone parcialmente con el Sur geográfico, el número de países y regiones que fueron sometidos al colonialismo europeo y que [...] no han alcanzado niveles de desarrollo económico similares a los países del Norte (Europa y América del Norte).

Campos (1997) trata acerca de la necesidad de comprender de donde viene las representaciones de nuestras vivencias y nuestras formas de entender el mundo, ya que, muchas veces, se produce una simple transferencia, siempre llena de fuertes connotaciones ideológicas, de referenciales del Norte epistémico al Sur epistémico sin la debida contextualización. Negligencias sistemáticas u ocasionales de contextualización pueden realizar estancamientos importantes en la construcción de saberes. Especialmente para la vida, y también para la investigación y la educación, la diversidad de contextos socioculturales requiere disposición para la dialogicidad y enfrentamientos de los obstáculos epistemológicos y del poder.

Freire (2011) también llama la atención sobre la connotación ideológica del término «nortear» y habla de la importancia de que, en la búsqueda para entender la visión del mundo de otros es imprescindible saber si nuestra lectura de mundo coincide o está familiarizada con la lectura de mundo de los grupos o la clase social con las cuales dialogamos ya que sólo desde el conocimiento contenido o implícito en ella me sería posible discutir mi lectura del mundo, que también mantiene y se basa en otro tipo de conocimiento.

Desde esta perspectiva, el Sur epistémico se presenta como una oportunidad para contrarrestar, para resistirse a la ideología del Norte epistémico, o sea como una forma de fortalecer estos grupos desde sus prácticas sociales y educativas emancipadoras.

Entendemos, por lo tanto, las Epistemologías del Sur, como $\ll[. .$.$] conjunto de intervenciones epistemológicas$ que $[\ldots]$ valoran los saberes que han resistido con éxito e investigan las condiciones de un diálogo horizontal entre conocimientos» (Santos \& Meneses, 2010: 19).

Tal marco epistemológico se pone en línea con las proposiciones de investigaciones en el ámbito de las Motricidades del Sur. Construyendo ese concepto también desde el inicialmente propuesto por GonçalvesJunior (2010) y Gonçalves-Junior et al. (2012: 252):

[...] desde la particularidad que constituye un grupo humano en una determinada localización espacio-temporal, en una dinámica relacional, simbólica y funcional singular. [...] ese estar ahí en el mundo de un grupo de seres humanos que les otorga identidad, historia, proyección diferenciada. Por lo cual, no es sólo conductas 
diferentes que pueden manifestar en relación con un determinado marco dominante, sino más bien es una percepción radical de mundo diferenciada que favorece determinadas comprensiones e interpretaciones de la acción humana, de su sentido y habitabilidad en el mundo. En consecuencia sólo sería posible comprender las acciones de un grupo social si nos adentramos profundamente en su mundo simbólico y comprehensivo de su día a día y cara a cara.

Así siendo, Motricidades del Sur, son entendidas como prácticas sociales de juegos, luchas, danzas, fiestas, cantos, historias y rituales con características propias de un pueblo/comunidad ubicada al sur, geográfica o metafóricamente, que involucran tradición y resistencia de tales manifestaciones al colonialismo y dominación epistemológica. La diversidad de experiencias de esas prácticas se configuran en forma particular tanto en su ejecución como en su intencionalidad en el proceso cotidiano de vivir-la-vida, en una perspectiva sureada (no norteada), en universo no dicotómico entre físico y mente, cuerpo y alma, persona y mundo, ser y naturaleza.

Además apreciar y retomar el mundo del canto, danza, juego y fiesta «[...] puede estimular en las personas la necesidad de estrechar relaciones y practicar la solidaridad, la convivencia, la coexistencia, la corresponsabilidad y por el proyecto colectivo de vivir bonito de los pueblos del sur» (Lemos, Gonçalves-Junior \& Rodrigues-Fernández, 2020).

Estas características fueron reveladas por AcuñaDelgado (2021: 474) quien, al investigar las competencias deportivas de los pueblos amerindios, destacó que, en particular, el fútbol practicado por los pueblos indígenas yanomami «[...] se presenta como un incentivo para aumentar los encuentros intercomunitarios e interétnicos, que puede inducir significativas transformaciones sociales y culturales».

Entendemos, de acuerdo con Oliveira et al. (2014), que las interacciones que surgen entre diferentes personas pueden entenderse como prácticas sociales que se desarrollan al interior de colectivos y comunidades, de manera que comparten significados, valores, conocimientos y epistemologías, buscando conquistar o garantizar derechos y el respeto y valoración de las personas y grupos socialmente marginados. Desde dentro de las más diversas prácticas sociales, escolares y no-escolares, se desarrollan procesos educativos, ya que todos los participantes involucrados son capaces de leer el mundo, reconocer a los demás y reconocerse a sí mismos, significar y resignificar su vida y dirigirse a lo ser-más.

Desde tales aportes, el objetivo de esta investiga- ción se ha centrado en la comprensión de los procesos educativos involucrados en la construcción de Motricidades del Sur, en particular en este artículo, de participantes de la Congada de San Benedicto en Ilhabela, municipalidad situada en la costa norte de São Paulo, Brasil.

Explicitamos que procesos educativos:

[...] ocurren en una relación mutua de aprendizaje y no sólo en una situación en que uno enseña al otro, tiendo como presupuesto fundamental para su desarrolo lo diálogo equitativo y la intencionalidad dirigida para la cooperación, superación, lo ser más, emanando autonomía, posibilidad de decisión y de transformación (Gonçalves-Junior, Carmo y Corrêa, 2015: 176).

\section{Procedimientos Metodológicos}

La construcción del conocimiento en esta investigación se configuró como un proceso socio-histórico que presentó realidades cargadas de sentidos/significados asignados por los diferentes individuos involucrados en la experiencia de campo intersubjetivo, como entienden Oliveira et al. (2014: 29): «[...] yo me construyo como persona en la convivencia con otras personas; $y$, cada uno, al hacerlo, contribuye a la construcción de 'uno' nosotros en el cual están todos implicados».

Así tenemos como principio de la investigación la proposición nombrada por Santos (2010) como ecología de saberes, cuya premisa es «[...] la idea de la diversidad epistemológica del mundo, el reconocimiento de la existencia de una pluralidad de formas de conocimiento más allá del conocimiento científico» (p. 54), y por lo tanto es $«[\ldots]$ crucial la comparación entre el conocimiento de que se está aprendiendo y el conocimiento de que este proceso se olvida y se han ido» (p. 56).

El vínculo con los participantes de la Congada se estableció en 2004 y se intensificó entre 2014 y 2017, en el contexto de esta investigación, inspirada en la metodología fenomenológica, con realización de entrevistas presenciales (ocurrieron antes de la pandemia COVID-19), con cinco personas ${ }^{2}$ involucradas con la práctica de la Congada en el municipio de Ilhabela, desde la cuestión: ¿Qué es Congada para usted?

En acuerdo con Pais (2001:110) la selección de los entrevistados/as en la investigación cualitativa empieza desde la importancia que tienen eses/as colaboradores/as en referencia al fenómeno estudiado, los criterios de selección son de vivencia, comprensión y pertenencia del fenómeno y no de significación estadística. Por lo tanto la muestra no tiene pretensión de genera- 
lizar los datos, pero si profundizar dada realidad, «[...] cuya singularidad es en sí mismo significativa».

Presentamos a continuación un breve perfil de los/ la entrevistados/a (Tabla 1.), señalando que los nombres son ficticios, de acuerdo con principios éticos en la investigación y, en este caso fueron elegidos por ellos/ ella mismos/a.

\begin{tabular}{|c|c|c|c|c|}
\hline \multicolumn{5}{|c|}{ fil de los entrevistados y entrevistada } \\
\hline Nombre & Entrevista & Edad & $\begin{array}{l}\text { Tiempo de Participación } \\
\text { en la Congada }\end{array}$ & Profesión \\
\hline Nina & I & 35 & Desde su nacimiento & Maestra de Educación Básica \\
\hline Baepi & II & 33 & Desde 2003 & Maestro de Educación básica y abogado \\
\hline Negro & III & 47 & Desde su nacimiento & Pedagogo, dramaturgo e historiador \\
\hline Rey & IV & 51 & Desde su nacimiento & Marinero \\
\hline Secretario & $\mathrm{V}$ & 40 & Desde su nacimiento & Policial militar \\
\hline
\end{tabular}

Tras la transcripción rigurosa y la lectura de las entrevistas, ellas fueron sometidos a análisis inspirada en la fenomenología (Bicudo \& Espósito, 1997), con los siguientes pasos: Identificación de las Unidades de Significado y Reducción Fenomenológica; Organización de Categorías y Construcción de Resultados guiada directamente en los datos identificados como convergentes, divergentes, idiosincrásicos.

Este proceso nos ha permitido la comprensión de los significados atribuidos a Congada de San Benedicto y la descripción de los procesos educativos que impregnan esta práctica social, configuradas en la categoría: «Ancestralidad, devoción y pertenencia en fiesta», que se discutirá a continuación.

Se observa, como ejemplo, que la cita a un extracto (unidad de significado) de la entrevista, se presenta la siguiente notación entre paréntesis: «(II-4)», en referencia a la entrevista dos, unidad de significado cuatro.

\section{Ancestralidad, devoción y pertenencia en fiesta}

En esta categoría emergen los procesos educativos involucrados con la ancestralidad de la Congada de San Benedicto, presentes en la historia y memoria colectiva de los antepasados, transmitidos de generación en generación, cuya tradición se mantiene viva y perdura en la comunidad, sustentada en el sentimiento de pertenencia con devoción a lo Santo Patrono de la Congada.

De acuerdo con el marco teórico que aportamos, la colonialidad del poder tiene como proyecto de dominación epistemológica la supresión de vivencias y saberes surgidos de manifestaciones del sur epistemológico, sobre todo de origen africana e indígena, por lo tanto con La Congada de San Benedicto en Ilhabela, ya que su origen está fuertemente involucrada a la esclavitud africana, conforme habla el entrevistado Negro adelante:
«[...] vino de África, en 1785. Vino... por un... un, negro, un esclavo que llegó a la isla en el sótano de un barco, directamente en la playa de Castelhanos, donde todos los negros fueron vendidos en esa, en el momento de la colonización acá en la isla» (III-4). Inicialmente bailada en los patios de las viviendas de los esclavos, con la liberación de los esclavizados «empezó a ensayar frente a la iglesia de San Juan en Perequê y las principales presentaciones fueron en las calles de la Vila [...]. Roldão Antonio de Jesús [...] trajo la Congada y comenzó a difundir la historia de la Congada entre todos los negros de la hacienda [...] donde él era un esclavo» (III-5).

La Congada es de origen bantú, de la región del Congo y Luanda siendo que «[...] la región del Congo fueron las comunidades africanas que más resistieron a la colonización portuguesa» (V-9). «La Congada fue una forma del negro expresar su cultura, dejar arraigada, transmitir a sus descendientes esa cultura y recordar sus orígenes $[\ldots]$ La gente caizara trata de recoger, mantenerlo allí para recordarle sus orígenes» (V-17) y que dura «[...] hasta hoy, con las mismas líneas, con los mismos uniformes con los mismos bailes, con los mismos pasos» (III-8), «[...] las personas manejan y busca mantener al máximo, ¿usted sabe? Cuanto más original, creo que tiene más sentido, ¿verdad?» (V-19).

La Ucharia de San Benedicto, donde se hace la producción y el depósito de los alimentos a la manifestación, es controlada hasta hoy por la familia de Eva Esperança Silva, cuya madre fue la primera jefe de Ucharia. De acuerdo con Nina «La Ucharia es una consecuencia de mi madre, es una consecuencia de mi abuela, mi bisabuela. E incluso porque usted como una mujer, no tiene espacio para hacer otras cosas» (I-2). Para Nina, una participación más grande de los congueros es necesaria porque «Vivimos en una realidad diferente, no se puede pensar que hace 200 años cuando llegó, hace 150 años, la Congada llegó y se quedaría igual, porque las cosas evolucionan, por lo que también es necesario adaptarse a eso» (I-25). Además, para que Congada continúe, se necesita organización, participación, autonomía y liderazgo, ya que muchos «quieren ayudar, pero no saben cómo» (I-31). Para Rey, cuya familia es en la actualidad una de las más grandes entre las participantes de la Congada, aunque un miembro o familia se vaya «Estamos ahí en la lucha del día a día, en la pelea» (IV-21).

La preocupación en mantener la tradición de la Congada que emerge de las entrevistas traduce la urgente necesidad de existir, pues se enteraron de que están vivos como grupo social por la «pelea del día a 
día» de sus ancestrales, sus antepasados.

Luchar contra el desperdicio de experiencias es en sí mismo una existencia con resistencia a un mecanismo perverso de caracterización errónea y desmovilización, que tiene el daño, sobre todo, la pérdida del sentido de pertenencia colectiva y comunitaria, sin el cual ni siquiera sabemos que tener algo por lo que luchar (Corrêa \& Gonçalves-Junior, 2020: 17).

Negro dice que «[...] cuando comenzó a llegar a la ciudad de Ilhabela toda esta tecnología, la televisión, los teléfonos móviles, ¿verdad? Y todo esto que tenemos hoy en día, gran parte de nuestra historia se fue $[\ldots]$ y lo que aún se está es la Congada de San Benedicto» (III21) que «[...] quedó en la memoria, representa el fundamento de la cultura tradicional de Ilhabela, no nos deja olvidar las otras, culturas [...] de la Isla que siempre tuvimos y ahora no tenemos más» (III-22).

Actualmente «Con el avance de la sociedad [...] es mucho, mucho más fácil para que usted pueda recoger y dejar de lado la parte de la religión, esta parte del respeto y de la familia, ¿verdad? Porque, las parejas en estos días, ¿verdad? El padre y la madre tienen que trabajar, por lo que no pasan tanto tiempo.Y la parte de la religión cada vez se queda fuera, ¿verdad?» (V-29).

Acerca la dispersión de los congueros más jóvenes, Nina dice: «Uno u otro terminan de dispersión, pensando que es un fantasía para estar allí, para estar exponiéndose en el mundo tecnológico, donde todo mundo filma y que puede llegar a ser, ya sabes, una broma en el grupo de amigos y no es así [...]. Me alegro de que me estás filmando, porque estás [...] mostrando lo que soy» (I-17).

Es importante tener en cuenta que aunque muchos de sus participantes vivan fuera del municipio éstos «[...] nunca dejan de venir, ya sabes, siempre están aquí; dos, tres, cuatro días antes de la Elevación del Mástil de elevación ellos ya están pululando por la ciudad» (III-40) y se unen a los que viven en Ilhabela.

Entre los cambios más recientes en la Congada tenemos la incorporación de la Congada Infantil que se estableció en 1999, cuando fueron llamadas por Negro «[...] los niños que tenían la sangre de Congada, que tenían la historia de Congada corriendo en la vena, los hijos de conguero, nietos de conguero, sobrinos de conguero, los niños que tenían la historia de la Congada en la sangre y organicé una Congadita» (III-18). Estos chicos actualmente conforman la Congada Adulta.

Baepi cree que tiene una obligación como maestro: «Garantizar el conocer de esta cultura y si posible garantizar la experiencia de toda esta cultura [...] lo que hemos tratado de hacer con los niños, para que ellos puedan conocer y hacia el conocer quizás amar. Amar toda esta historia [...] de sus abuelos, bisabuelos, de sus padres. También puede llegar a ser de ellos» (II-21).

El relato de Baepi remete a lo sentido presentado por Krenak (2020) a cerca de la ancestralidad como continuidad de lo legado de los antepasados, cuyos conocimientos son reverenciados como condición para el buenvivir de los pueblos originarios. Observamos la valoración de tales preceptos en la experiencia de los participantes de la Congada cuando Negro afirma que considera papel del maestro transmitir a los niños valores tales: «Esta cosa de la bondad, de la humildad. De compartir con el pequeño amigo las cosas que tiene que, de ayudar al pequeño amigo dentro del aula. Tenemos que unirnos más y más [...]Tenemos que tomar, tomarse de las manos... para abrazarnos más, besarnos más, nos gustarnos más. Eso es lo que San Benedicto quiere!»(III62).

En lo que respecta al mantenimiento de la Congada, Secretario dice: «[...] si depende de mí y mi voluntad eso seguirá habiendo allí hasta [...]. Dejo solamente cuando, cuando en realidad no puedo más de hacerlo» (V-26), pues de ser elegido como Secretario por su predecesor, ahora tiene la responsabilidad «recoger y mover a los otros ese sentimiento, que es lo que, es lo que nos impulsa y es por eso que todavía existe [...], tenemos la responsabilidad de recoger y transmitir este significado para los, para los más jóvenes» (V-28). Para eso «[...] usted no tiene que recoger y abrir y coger la cabeza de los niños y decir 'mira, tiene que ser así, tiene que ser así.' No, si lo hacemos y ellos cogen y se dan cuenta, lo que realmente se nota, lo conseguirán eso y también lo repasará, yo creo, que fue así en los últimos años» (V-32), pues Secretario cree que la gestualidad y la danza, «[...] la magia que hay entre nosotros es lo que hace recoger y continuar de generación en generación» $(\mathrm{V}-24)$.

«Un baile que hacemos, una ronda de la espada que hacemos, la forma de hablar, ¿verdad? Tratamos de recoger hoy en día, ¿verdad? Hoy trato de coger y pasar esto a los jóvenes [...] Una manera de la gente recoger y danzar que ya está siendo copiado por los más nuevos [...]. Hace cuatro o cinco años, el primer año que yo era Secretario, hice algo diferente, hoy en día todo el mundo lo hace. Así que creo que es esta manera de ser recordado, es interesante para nosotros, ¿verdad?» (V-8).

Por tanto, la danza, el gesto, la vestimenta traduce la memoria de un pueblo y su legado, que no se puede olvidar para que podamos afirmarnos en nuestra identi- 
dad y fortalecernos como persona que pertenece a un lugar, a una comunidad, conforme enseña poéticamente Krenak (2020: 29):

«Cantando. Bailando. Pasando por encima del fuego. Continuamos en un continuo. El rastro de nuestros antepasados». Este pequeño poema es una canción. Siempre nos recuerda que cuando caminamos aquí hoy, seguimos los pasos de nuestros antepasados. Y este «cantar, bailar y pasar sobre el fuego» es literalmente caminar sobre el brasero, que es un rito de paso para la transmisión de este conocimiento que, de generación en generación, se transmite. Para que podamos seguir recordando quiénes somos [...].

El mantenimiento de la tradición conguera también se produce a través de los trajes y accesorios usados como una sola pieza, pues de pasar a otros miembros de su familia «[...] termina por tener un valor y significado, por tener una historia. Nos fijamos en esa ropa, nos fijamos en la ropa, nos fijamos en una espada, a recordar varios eventos»(V-21).

Podemos observar descripciones de la devoción a San Benedicto y el sentimiento de pertenencia personal/comunitaria en la Congada. Existen aserciones de los/la participantes sobre el papel del Santo en sus vidas, cuando nos dicen, por ejemplo: «[...] todo lo que implica mi vida, tiene San Benedicto en el medio» (III2); «Yo no tendría sentido en mi vida, si no tuviera una creencia en San Benedicto» (I-2). Esta devoción les da fuerza, $\ll[\ldots]$ a pesar de que hay personas que entienden esta devoción como superstición, para los congueros, ella es el medio a través del cual buscan protección, salud para sí mismos, para su familia y amigos» (V-6).

La implicación con la devoción llega muy temprano, a través de la familia y por lo general continúa hasta el final de la vida. Para algunos participantes de la Congada la devoción es la entrega total a al Santo. Según Rey «[...] la devoción no es el misma para todo el mundo, hay quienes la sostienen con más cariño y quienes con menos» (IV-2). Ya Baepi menciona los devotos del Santo como «[...] servidores de San Benedicto» (II-9) y nos dice acerca de cómo los devotos «[...] aprenden de alguna manera a adorar, reverenciar este tipo que solamente dedicó su vida a hacer el bien en general» (II-8).

Todos los/la encuestados/a describen que la esencia dela Congada es la devoción a San Benedicto, presentándolo como el santo patrón, aunque sea hecho el reconocimiento de otros aspectos que intervienen en Congada como el social y el cultural por algunos de ellos. Secretario nos dice que el respeto a los familiares y amigos que se han ido, la devoción y la tradición se entrelazan en la Congada y que él busca «transmitir esto a los más pequeños, a los más joven» (V-7).

Baepi indica que el aspecto cultural de la Congada es muy fuerte y lo hace encontrarse «[...] con situaciones que $[\ldots]$ ya experimentaba incluso antes mismo de conocer la Congada $[\ldots]$ y sentirse cada vez más cerca de sus raíces y antepasados» (II-2). En su opinión, se puede observar la Congada desde un aspecto social y luego ver cómo esto «[...] puede ser movilizador y como esto puede crear una identidad» (II-6). Este trabajo realizado en silencio por la Congada se presenta cuando:

«[...] la gente dice "quiero experimentar cosas que creo, quiero experimentar lo que es mi tradición, quiero experimentar lo que es bueno para mí y me han proporcionado desde [...] una linaje que no se inició ahora, aquí'. No, se trata de mi bisabuelo viene de la gente mucho más antiguas y entonces se puede ganar esta mufla voces, puede superar esta mufla voces, dejando cada vez más personas con ese sentido [...] Sí, soy afrodescendiente; si soy devotado a Benedicto, también soy un católico y yo quiero vivir esta experiencia de fe [...] que, para algunos es una experiencia social, una experiencia cultural o incluso una experiencia política [...] la gente vamos conociendo y vamos a... cuanto más daremos cuenta de la lucha para que se convertiría en lo que es hoy» (II-17).

Para él, como la devoción y la Congada no son impuestas y se han construido a lo largo de la historia, esto permite que «[...] las personas desarrollan ah, el sentimiento de per-te-nen-cia [...].Y es este 'yo hago parte' que garantiza [...] largo de la historia, el crecimiento de la Congada» (II-18).

Baepi dice que «[...] los devotos no son necesariamente católicos, a pesar de que puede haber nacido en familias católicas» (II-13) y sigue afirmando que esa devoción tanto era algo bien aceptado por los blancos, como que hubo momentos de prohibición de esta forma de devoción por los representantes de la Iglesia Católica, por ellos comprendieren que la forma como los negros se manifestaban en esta religiosidad traía muchos elementos característicos de las religiones de origen africano y, a continuación, han reaccionado en el sentido de decir: «[...] que no, que no me conviene, que... no se puede practicar aquí en frente de nuestra iglesia o dentro de nuestra iglesia, o con nuestro consentimiento» (II-16).

Baepi también pone de relieve la acogida y como el grupo ahora entiende que «[...] es mejor acoger que rechazar» (II-13).

Además los/a entrevistados/a exaltan el proceso 
educativo de la comunión, de compartir, de encuentro y reencuentro para hacer juntos, a saber: planificar, construir, trabajar, rezar y divertirse en la Congada, cuestiones que no se producen de forma aislada, sino integrada en el hacer-con, que se materializa en la fiesta.

De acuerdo con Nina, la Congada es un conjunto de elementos: «Es una manifestación de la calle es la Ucharia es la masa de congueros [...] y muchas personas piensan que es sólo la presentación del teatro, el drama» (I-10).

«[...] tiene toda la preparación del anda, como ya he dicho, el viernes a las $5 \mathrm{pm} . . . \mathrm{y}$, el afecto que la gente, adornarán el Santo... y que la persona hará una concertada, la persona que va a hacer el pastel, que resultó tradición, la persona que pintó el mástil, es... El sábado y el domingo, ya sabes, más allá de la manifestación en la calle, la gente termina de ver detrás de las escenas, y es fundamental! No tenemos una fiesta justo a tiempo...» (I-8).

En consonancia con los apuntamientos de Lemos, Gonçalves-Junior \& Rodrigues-Fernández (2020) la comunión es uno de los factores clave y necesarios en la realización de la fiesta, así como dice Nina: «[...] no deja de ser una comunión, a continuación, por lo que, más allá de la creencia, más allá de la devoción, es un tiempo para estar en comunión, ¿verdad? [...] tenemos también, esta vez para estar juntos, en la celebración de San Benedicto (I-5), [...] donde cada uno busca para ser capaz de hacer su parte, todo el mundo sabe que es importante, ¿verdad? Usted tiene su tiempo para poder participar y que cada uno se irá con un buen partido y que continuará la tradición» (I-6).

Para Nina y Negro, la Congada es un momento de encuentro con muchas personas que viven fuera de la ciudad y la Ucharia más de un espacio de almacenamiento y distribución de alimentos se refiere a «[...] un momento para estar en comunión con la familia. Anteriormente fue así. Ahora que fue abierta al público que se acaba de tomar esta esencia» (I-9), se perdió esa cosa de «[...] vamos a estar en comunión sólo congueros y las familias de congueros» (I-22).

Baepi habla de que la Congada promueve un momento de congratulación y comunión único porque «[...] capaz de movilizar una ciudad en su conjunto [...] y personas que ya no viven $[\ldots]$ en este municipio para que puedan estar juntos, en virtud de esas festividades, ese momento» (II-3) de modo que «[...] en un cierto tiempo la gente tan imbuida con, tan involucrada y usted ya no puede percibir la división de las clases sociales en la realización de la misma, ya no se puede ver la división necesariamente por colores de tono de la piel en el hacer las cosas» (II-4).

Podemos observar que la ancestralidad y los gestos se entienden como polos en los procesos educativos de mantenimiento, transmisión y resistencia de los participantes de la Congada y sus familias en la búsqueda de su lugar en la sociedad y la apropiación de su historia, con luchas personales de sobrevivencia, así como por la continuidad de la tradición de la Congada, se ve reforzada por el sentimiento de pertenencia a un grupo que se materializa en la devoción al santo y en la fiesta en comunión.

\section{Consideraciones}

Frente a la interrelación y los significados de nuestra experiencia con los participantes de la Congada de San Benedicto en Ilhabela, la búsqueda de desvelar los procesos educativos, escuchándolos, desde la perspectiva de la ecología de los saberes, de las epistemologías del sur (Santos, 2010) y nuestra proposición de las Motricidades del Sur es traducida en la esencia del proceso de investigación que nos proponemos llevar a cabo.

La Congada presentase, desde su llegada en Ilhabela, como un punto de convergencia entre el pasado, presente y futuro, que está hecha y rehecha por los/las propios/as participantes de la Congada cuyas rememoraciones demuestran los procesos educativos de tradición y resistencia de esta manifestación, como dice Negro, la Congada esta: «[...] corriendo en la vena, en la sangre» (III-18). Metafóricamente recordando el pasado de sus antepasados como en lo principio filosófico africano sankofa e indígena de lo buen-vivir (conforme presentado por Tedla, 1995 y Krenak, 2020), señala la afirmación de identidade, así como la afirmación de la devoción a San Benedicto.Y, conforme Dussel (s/d), la cultura popular $\ll[\ldots]$ irradia la resistencia de los marginalizados contra la opresión».

Por varios momentos, las cualidades exaltadas en San Benedicto son valorados, aprendidas y enseñadas entre los/las participantes de la Congada en la vida cotidiana, produciendo o reproduciendo, creando o recreando los procesos educativos como: la generosidad, que nos habla de dar y compartir; la humildad, que hace hincapié en que debemos ser respetuosos/as con todo y todos/ as; el coraje que viene de conocerse a sí mismo anclado en su comunidad y consciente de sus derechos y obligaciones a ella y con la vida en su conjunto: «Puedo ser yo solo porque lo somos» (Tutu, 2012: 42), al sentir y bailar con el Otro, puedo ser (Senghor, 1965).

La Congada se establece a partir de la posibilidad de 
constituirse como un espacio de comunión y aprendizaje mutuo en esta convivencia, porque al recibir las personas que no son de familias de Congada, sus miembros también están abiertos a otras percepciones de la espiritualidad y la negritud. Como dice Freire \& Faundez (1985) en la espiritualidad también encontrase la resistencia popular. Es y porta en su práctica ancestralidad, la fuerza necesaria para aproximar las personas y les inspirar el desafío de mantener las tradiciones de la comunidad.

La devoción a San Benedicto está arraigada en la vida cotidiana de los participantes de la Congada, desde niños/as comienzan la experiencia espiritual y devoción en la familia, ya que es en sus prácticas cotidianas y en los espacios de la Congada en donde aprenden a comportarse, a vestirse. Mientras que aprenden en sus hogares, aprenden durante la manifestación de la espiritualidad en la Congada con la orientación de los mayores. Estas directrices se refieren a como danzar, en la empuñadura y el giro de la espada, la presentación de las embajadas, en el canto o en la forma de contonear. También se refieren a la forma de trabajar en Ucharia, ser reina y respetar la tradición de alabar al santo.

Como Motricidades del Sur, tales como nos presentan Gonçalves-Junior et al. (2012), en la Congada de San Benedicto en Ilhabela involucrase la tradición y la fuerza de un pueblo; estos aspectos están bien mantenidos, son criados, recreados, rememorados, se hacen presentes y se proyectan entre sus participantes en el proceso cotidiano de vivir-la-vida.

Consideramos que esta experiencia, Congada, que se da en ámbito no-escolar, tiene fundamentales contribuciones de conocimientos, perspectivas y procesos educativos que pueden y deben ser reconocidos también en el ámbito escolar, valorando las personas afrodescendientes y sus contribuciones con motricidadesepistemologías del sur.

\section{Agradecimientos}

La investigación fue apoyada, con beca doctoral, por el Consejo Nacional de Desarrollo Científico y Tecnológico (CNPq-Brasil) y, con beca de doctorado sándwich a la Universidad Austral de Chile, por la Coordinación de Perfeccionamiento del Personal de Educación Superior (CAPES-Brasil).

\section{Referencias}

Acuña-Delgado, A. (2021). La competencia deportiva en pueblos amerindios: casos heterodoxos para entender otras lógicas de actuación, Retos, 43, 463-476. https: / / recyt.fecyt.es/index.php/retos/article/ view/89221/66004.

Adams, C. (2000). As populações caiçaras e o mito do bom selvagem: a necessidade de uma nova abordagem interdisciplinar. Revista de Antropologia, 43(1), 144-182.

Belmonte, M.M. (2019). Fútbol callejero: processos educativos de uma motricidade emergente. Tese (Doutorado em Educação). São Carlos: UFSCar.

Bicudo, M.A.V. \& Espósito, V.H.C. (Org.). (1997). Pesquisa qualitativa em educação. 2 ed. Piracicaba: UNIMEP. Campos, M.D. (1997). SULear vs NORTEar: representações e apropriações do espaço entre emoção, empiria e ideologia. Série Documenta, año VI, núm. 8. EICOS, Cátedra UNESCO de Desenvolvimento Durável, UNIRIO, Rio de Janeiro, 41-70. http://www.sulear.com.br/texto03.pdf.

Campos, S.E.A. (2008). Ser caiçara em Ilhabela: as construções de identidades nas tensões entre o passado e o presente. Dissertação (Mestrado em Educação). São Carlos: UFSCar.

Campos, S.E.A. (2017). Congada de São Benedito em Ilhabela: processos educativos entre participantes. Tese (Doutorado em Educação). São Carlos: UFSCar.

Carmo, C.S. (2017). Epistemologia da bicicleta: processos educativos emergentes na prática do pedalar. Tese (Doutorado em Educação). São Carlos: UFSCar.

Corrêa, D.A; Gonçalves-Junior, L. (2020). Por uma constelação de conhecimentos na universidade: experiências de estudantes indígenas em programa de ações afirmativas. Revista Cocar, 14(30), 1-19. https: / / periodicos.uepa.br/index.php/cocar/ article/view/3654.

Corrêa, I.F.L. (1981). A congada de Ilhabela na festa de São Benedito. São Paulo: Escola do Folclore/Livramento.

Diegues, C. (2005). Esboço de história ecológica e social caiçara. En C. Diegues, (Org.). Enciclopédia caiçara - história e memória caiçara (pp. 273-319). São Paulo: Hucitec.

Dussel, E. (s/d). Para uma ética da libertação latino-americana III: erótica e pedagógica. São Paulo: Loyola; Piracicaba: UNIMEP.

Freire, P. \& Faundez, A. (1985). Por uma pedagogia da pergunta. Rio de Janeiro: Paz e Terra.

Freire, P. (2011). Pedagogia da esperança: um reencontro com a pedagogia do oprimido. (17a ed.). Rio de Janeiro: Paz e Terra.

Gonçalves-Junior, L. (2010). Etnomotricidade: 
multiculturalismo e educação física escolar. En D.C. Filho \& W.R. Correia (Org.), Educação física escolar: docência e cotidiano (pp. 49-67). Curitiba: CRV.

Gonçalves-Junior, L., Corrêa, D. A., Carmo, C.S., Campos, S.E.A. \& Toro-Arévalo, S.A. (2012). Etnomotricidad: juegos de resistencia cultural en la comunidad caizara de Ilhabela - Brasil. Estudios Pedagógicos, 38 ( $\mathrm{n}^{\circ}$ especial 1), 249-266. http:// revistas.uach.cl/pdf/estped/v38nEspecial/art14.pdf

Gonçalves-Junior, L., Carmo, C.S., \& Corrêa, D.A. (2015). Cicloviagem, lazer e educação ambiental: processos educativos vivenciados na Serra da Canastra. Licere, 18(4), 173-208. https:// seer.ufmg.br/index.php/licere/article/view/ $1282 / 965$

Krenak, A. (2020). Caminhos para a cultura do bem viver. http: / / www. culturadobemviver.org/pdf/ Caminhos_para_a_dultura_do_Bem_Viver_Ailton_Krenak.pdf

Lemos, F.R.M., Gonçalves-Junior, L. \& RodriguesFernández, J.E. (2020). Praxis con ociomotricidad: procesos educativos movilizados con estudiantes de pregrado en educación física del interior de São Paulo, Brasil. Retos, 38(1), 733-738. https: / / recyt.fecyt.es/ index.php/retos/article/view/73970/49507

Merlo, M. (2000). Memória de Ilhabela: faces ocultas, vozes no ar. São Paulo: EDUC/ FAPESP.

Oliveira, M.W., Silva, P.B.G., Gonçalves-Junior, L., Montrone, A.V.G., \& Joly, I.Z.L. (2014). Processos educativos em práticas sociais: reflexões teóricas e metodológicas sobre pesquisas em espaços sociais. En M.W. Oliveira \& F.R. Sousa, (Org.), Processos educativos em práticas sociais: pesquisas em educação (pp. 29-46). São Carlos: EDUFSCar.

Pais, J.M. (2001). Ganchos, tachos e biscates: jovens, trabalho e futuro. Porto: Ambar.

Santos, B.S. (2004). Introdução. En B.S. Santos, (Org.), Conhecimento prudente para uma vida decente: um discurso sobre as ciências sociais revisitado (pp. 17-56). São

\section{Paulo: Cortez.}

Santos, B.S. (2010). Para além do pensamento abissal: das linhas globais a uma ecologia de saberes. En B.S. Santos \& M.P. Meneses (Org.), Epistemologias do sul (pp. 31-83). São Paulo: Cortez.

Santos, B.S., \& Meneses, M.P. (2010). Introdução. En B.S. Santos \& M.P. Meneses (Org.), Epistemologias do sul (pp. 15-27). São Paulo: Cortez.

Senghor, Leopold S. (1965). Um caminho do socialismo. Rio de Janeiro: Record.

Sérgio, M. (1996). Epistemologia da motricidade humana. Lisboa: FMH Edições.

Tedla, E. (1995). Sankofa, african thought and education. New York: Peter Lang.

Tutu, D. M. (2012). Deus não é cristão. Rio de Janeiro: Thomas Nelson Brasil.

Walsh, C. (2017). Pedagogías decoloniales: práticas insurgentes de resistir, (re)existir e (re)vivir. Equador: AbyaYala.

\section{(Footnotes)}

${ }^{1}$ Resaltamos que ser europeo, o sea, ter nascido en suelo europeo, es una cosa, ser eurocéntrico es otra completamente distinta, que implica en la adopción de un sistema ideológico para dar sustentación a la invasión, esclavización y colonización territorial y cultural de los pueblos no europeos desde el siglo XV, lo cual persiste hasta hoy descalificando personas y conocimientos africanos, indígenas, populares y caizaras, clasificándolos como inferiores y primitivos, en cuanto los eurocéntricos son clasificados como superiores y civilizados.

${ }^{2}$ Después de la aprobación del Comité de Ética para la Investigación con Seres Humanos de la Universidad Federal de São Carlos/Plataforma Brasil, a través del Dictamen No. 939.372, firma de los entrevistados en Formulario de Consentimiento Libre e Informado, así como elección de nombre ficticio por el entrevistado.
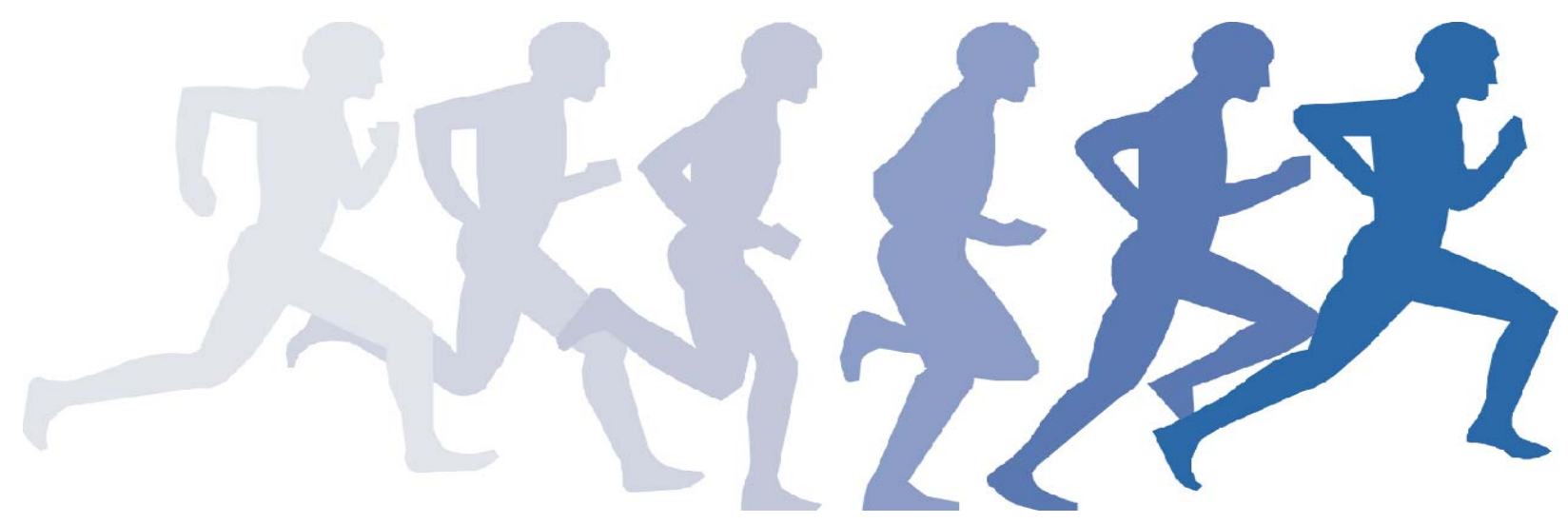